\title{
Review
}

\section{Deliberative democracy between theory and practice}

\author{
Michael A. Neblo \\ Cambridge University Press, New York, 2015, xvi+215pp., \\ ISBN 978-1107027671
}

Contemporary Political Theory (2018) 17, S143-S145. https://doi.org/10.1057/s41296017-0128-9; published online 27 June 2017

Michael Neblo's book has been long anticipated, not least because of the glimpses we have had of his thinking on deliberative democracy over the last decade and more. At a time when the study of deliberative minipublics was all the rage, Neblo was pressing an alternative and then-unfashionable view that eventually matured into the deliberative systems approach, drawing on a phrase from Jane Mansbridge. He did so well before my own work made it into print, let alone the major reshaping of deliberative theory that followed with scholars like John Dryzek, Carolyn Hendriks, James Bohman, Stefan Rummens and many others joining the chorus.

Neblo's main target is a view of democracy that has long reigned in comparative political science, particularly but by no means exclusively in the United States. This view holds that 'the people' cannot be trusted with direct engaged democracy, because surveys show time and again that people are not knowledgeable enough about politics, have inconsistent or even incoherent preferences, are self-interested rather than civic-minded and unwilling to spend the time addressing any of that. But he then argues that not only is the evidence for those positions weaker than it is commonly supposed, but also the deliberative democratic response was weaker than it should have been. Instead of presenting an alternative vision of mass democracy in which citizens talk about recognisably political topics every day, deliberative democrats either ran for the hills or huddled indoors. They did the first by insisting that theirs was a normative theory, unaffected by empirical objections; the second by retreating into the special conditions of small-scale, participatory experiments in which the sceptics' empirical objections did not hold. The result was that deliberative democrats ceded the field to the elitists.

Neblo's solution is, broadly speaking, the same as that of other systems theorists: stop thinking of deliberative ideas as blueprints for the design of democratic

(C) 2017 Macmillan Publishers Ltd. 1470-8914 Contemporary Political Theory Vol. 17, S3, S143-S145 
innovations, because no single institution can possibly meet all the desiderata at once. Instead, Neblo argues, one should think of them as ideals that democratic systems should aim for. Doing so allows deliberative democrats to re-enter the field, as it were, armed with empirics which show that people are interested, active and engaged when are given space and set the terms of engagement; that they appeal to deliberative ideals when criticising government and that it is at the system level that we should look for deliberative quality, not in individual events and practices. The problem from this perspective is not that citizens do not care; it is that they are not given effective opportunities to discuss, endorse or criticise courses of action, and that they are asked the wrong questions by political scientists focused on formal institutions of government.

Given that, however, it is surprising that Neblo offers a model of 'the' deliberative system focused on formal sites, institutions and communicative linkages. Perhaps this is where the slow gestation of the book shows most clearly, because such static, formal network models are being challenged by sequenced, discursive, performative and plural models which, to one degree or another, emphasise dynamics, agency, contingency and creativity rather than a single set of formal institutional relationships. His focus leads him to entitle one chapter 'form follows function', but that implies a kind of determinism that is not only unjustifiable on empirical grounds, but sits uncomfortably with his otherwise-admirable respect for the surprising (to political science) ways that real people act, and construct meaningful narratives of action. An alternative, interpretive vision has recently been advocated most forcefully by Boswell and Corbett (2017).

And it is on such questions of action that Neblo presents impressive theoretical and conceptual argument, and evidence from empirical work that he and collaborators have done, to call the sceptics' bluff. Non-North Americans might find his particular take rather too much in thrall to psychology, especially given how much psychological evidence is generated in controlled rather than real-world conditions. And when it comes to the discussion of Riker et al. in chapter four we are not really breaking very much ground that Mackie has not already broken. But in chapter five we get some genuinely interesting results on the willingness to deliberate given the relative paucity of opportunities to do so.

But perhaps to say that Neblo's model is too formal and not alive enough to practices of meaning making would be to ask him to disengage from political scientists for whom interpretivism is akin to reading tea leaves. Perhaps what is needed to shift the sceptics from their dismissive attitudes is precisely the kind of analysis that Neblo offers. His aim is to take on the sceptics on their own ground, in their own terms, and he pursues that goal with precisely the kind of thorough grasp of both theory and empirical research that gives him the best chance of hitting his 
target. At the same time, he provides a refreshing and clear argument for thinking that the deliberative systems approach is the way forward if deliberative theory is to achieve its lofty, emancipatory goals.

John Parkinson

Griffith University, Nathan, Brisbane, QLD 4111, Australia john.parkinson@griffith.edu.au 